\title{
Behavioural and toxicological responses of Blattella germanica (Dictyoptera: Blattellidae) to monoterpenes
}

\author{
Raúl A. AlZOGARAY ${ }^{1,2}$, VAleria SFARA ${ }^{1,2}$, Ariadna N. MORETTI ${ }^{1}$ and Eduardo N. ZERBA ${ }^{1,2}$ \\ ${ }^{1}$ Centro de Investigaciones de Plagas e Insecticidas (CIPEIN-CITEDEF/CONICET), J.B. de La Salle 4397, (1603) Villa Martelli, \\ Prov. de Buenos Aires, Argentina; e-mails: ralzogaray@hotmail.com; vsfara@citedef.gob.ar; amoretti@citedef.gob.ar; \\ ezerba@citedef.gob.ar \\ ${ }^{2}$ Instituto de Investigación e Ingeniería Ambiental, Universidad Nacional de San Martín, San Martín, Prov. de Buenos Aires, \\ Argentina
}

Key words. Dictyoptera, Blattellidae, Blattella germanica, German cockroach, locomotor activity, monoterpenes, repellency, knock-down

\begin{abstract}
Certain monoterpenes produced by aromatic plants are known to have lethal and sublethal effects on insects. As there is a need to replace conventional pesticides (organophosphates, carbamates, pyrethroids) with biorational pesticides, we evaluated the behavioural and toxicological responses of the German cockroach, Blattella germanica, exposed to the following monoterpenes, namely $(+)$ - $\alpha$-pinene, $(-)-\alpha$-pinene, limonene, menthone, linalool, menthyl acetate and geraniol. Locomotor activity and repellency were quantified using a video tracking system. To study the effect on locomotor activity, larvae were exposed to filter papers treated with concentrations of monoterpenes ranging between 1.4 and $1,400 \mu \mathrm{g} / \mathrm{cm}^{2}$. Only menthyl acetate applied at a concentration of 14 $\mu \mathrm{g} / \mathrm{cm}^{2}$ or higher increased the locomotor activity of the larvae. Repellency was evaluated by exposing larvae to circles of filter paper divided in two equal zones: one zone was treated with a solution of a monoterpene in acetone $\left(14\right.$ or $\left.140 \mu \mathrm{g} / \mathrm{cm}^{2}\right)$ and the other with only acetone. Larvae were repelled by all the monoterpenes tested. The two concentrations of geraniol and the highest concentration of menthyl acetate and linalool were as repellent as DEET (positive control). The fumigant effect was evaluated by exposing larvae to vapour from $100 \mu \mathrm{l}$ of pure monoterpene in a sealed container. The values of the 50\% Knock-down Times (KT50), expressed in minutes, were: $(+)$ - $\alpha$-pinene: $11.8,(-)-\alpha$-pinene: 14.6, limonene: 81.0 , menthone: 141.0, and linalool: $238.6 .(+)-\alpha-$ Pinene was as good a fumigant as dichlorvos (positive control, KT50 = $9.7 \mathrm{~min}$ ). The least effective compounds were menthyl acetate and geraniol (both affected less than $50 \%$ of larvae after $490 \mathrm{~min}$ of exposure). In conclusion, (+)- $\alpha$-pinene (for its fumigant effect), menthyl acetate (for its hyperactivant effect) and menthone and geraniol (for their repellent properties) could potentially be used for controlling $B$. germanica.
\end{abstract}

\section{INTRODUCTION}

During their coevolution with pathogens and herbivores, plants developed the ability to produce secondary metabolites that protect them from the activity of these organisms (Isman \& Akhtar, 2007). Some of these substances are components of essential oils, complex mixtures of monoterpenes $\left(\mathrm{C}_{10}\right)$, sesquiterpenes $\left(\mathrm{C}_{15}\right)$, including biogenetically related phenols (phenylpropenes and cinnamates), produced by plants belonging to the families Lamiaceae, Myrtaceae, Rutaceae and Apiaceae (Isman \& Machial, 2006). Terpenes from plants are used in food, pharmaceutical and perfume industries. Some monoterpenes have lethal and sublethal effects on insects (Isman, 2006).

Monoterpenes have high vapour pressures (Tisserand \& Balacs, 1995). This feature is favourable for their application as fumigants. Different monoterpenes are effective fumigants against stored product pests (Lee et al., 2003; Rajendran \& Sriranjini, 2008), mosquitoes (Lucía et al., 2007; Zahran \& Abdelgaleil, 2011), German cockroaches (Phillips \& Appel, 2010; Alzogaray et al., 2011); houseflies (Tarelli et al., 2009), blood-sucking bugs (Sfara et al., 2009) and human lice (Toloza et al., 2006).
Sublethal effects produced by monoterpenes include prevention of either feeding or oviposition (Petrakis et al., 2005; Isman et al., 2007), weight loss (Karr et al., 1990), inhibition of development (Hummelbrunner \& Isman, 2001; Zahran \& Abdelgaleil, 2011) and repellency (Cornelius et al., 1997; Choi et al., 2002; Chen \& Viljoen, 2010; Alzogaray et al., 2011).

Monoterpenes generally are less toxic to mammals than conventional insecticides (organophosphates, carbamates and pyrethroids) and once released into the environment are relatively quickly degraded (Isman, 2000). Their mode of action has not been extensively studied, but there is evidence that some monoterpenes block octopamine and/or tyramine receptors (Enan, 2001, 2005), while others inhibit acetylcholinesterase activity (Picollo et al., 2008; López \& Pascual-Villalobos, 2010). These properties, along with their repellent and fumigant effects, make monoterpenes potential replacements for conventional insecticides, which contaminate the environment and are toxic to organisms other than pests. Most essential oil components are considered to be minimum risk pesticides according to section 25(b) of the Federal Insecticide, Fungicide, and Rodenticide Act of United States (Isman \& Paluch, 2011). 
The German cockroach, Blattella germanica, is an important sanitary pest. It is cosmopolitan and abundant in homes and other human installations (Cochran, 2003). Besides contaminating the places they live in with their excrements and exuviae, they are a mechanical vector of a number of human pathogenic microorganisms and also produce allergens (Brenner, 1995).

The objectives of the present study were to evaluate the effect of monoterpenes on locomotor activity, as repellents and in their knock-down effect on first instar larvae of B. germanica. The monoterpenes studied were: $(+)-\alpha-$ pinene, $(-)-\alpha$-pinene, limonene, menthone, linalool, menthyl acetate and geraniol. We choose these compounds because they showed insecticidal activity in experiments performed in our laboratory using head lice, Pediculus humanus capitis De Geer (Toloza et al., 2006), bloodsucking bugs, Rhodnius prolixus Stahl (Sfara et al., 2011), houseflies, Musca domestica L. (Tarelli et al., 2009) and horn flies, Hematobia irritans L. (unpubl. results).

\section{MATERIAL AND METHODS}

\section{Biological material}

One- to 4-d-old B. germanica first instar larvae, obtained from a colony kept at Centro de Investigaciones de Plagas e Insecticidas (CIPEIN-CITEDEF; Villa Martelli, Buenos Aires, Argentina), were used in all the experiments.

\section{Chemicals}

Monoterpenes were all purchased from Sigma-Aldrich (Buenos Aires, Argentina): (1R)-(+)- $\alpha$-pinene (98\%), (1S)-(-)a-pinene (98\%), (S)-(-)-limonene (96\%), (-)-menthone (90\%), linalool (97\%), (1R)-(-)-menthyl acetate (98\%) and geraniol (98\%). Acetone was obtained from Merck (Darmstadt, Germany), $N, N$-diethyl- $m$-methylbenzamide (DEET) from Aldrich and dichlorvos (technical grade) was provided by Chemotecnica SA (Spegazzini, Argentina).

\section{Recording equipment}

A closed-circuit black and white video camera (VC 1910; Sanyo Electrical Co., Tokyo, Japan) and an image analyzer (Videomex V, Columbus, $\mathrm{OH}$ ) were used to evaluate the insect's behaviour. The video camera was used to record the positions of insects placed on a circular piece of filter paper. The image analyzer converts the analogue signal input from the video camera into digital data. Resolution is 256 per 192 pixels, and the acquisition and processing speed is $30 \mathrm{frames} / \mathrm{sec}$. In the monitor, the video signal colours are inverted and therefore white objects appear to be black and vice versa. The presence of larvae on a filter paper is determined by the visual contrast between the individuals (white) and the paper background (dark). To quantify larval movement, the image analyzer uses the Multiple Zones Motion Monitor for Videomex software to compare consecutive frames and records the number of pixels that changed from "on" to "off" and vice versa. This parameter is called "movement". The software also calculates the average number of pixels "on" during the experiment. This parameter is called "area". Due to changes in the positions of the larvae, the number of total pixels "on" varies during an experiment. To standardize the data for the size of the larvae the results were expressed in terms of the quotient "movement"/"area" (Alzogaray et al., 1997). Each set of data was imported to and processed on a personal computer.

\section{Locomotor activity}

A circle of Whatman \# 1 filter paper (Whatman International, Maidstone, UK), $7 \mathrm{~cm}$ in diameter was treated with $0.5 \mathrm{ml}$ of either a solution of a monoterpene in acetone or acetone alone (control). Concentrations between 1.4 and $1,400 \mu \mathrm{g} / \mathrm{cm}^{2}$ of each monoterpene were tested, except when stated otherwise. After the acetone evaporated, the filter paper was placed in the experimental arena. A glass ring, $2.5 \mathrm{~cm}$ high and $5.0 \mathrm{~cm}$ diameter, was placed on the filter paper to prevent the larvae from escaping. Four larvae were gently placed on the area of the filter paper encircled by the ring and their movement was recorded for $30 \mathrm{~min}$. There were six independent replicates of each experiment.

\section{Repellency}

A circular piece of Whatman \# 1 filter paper, $7 \mathrm{~cm}$ in diameter, was divided in two equal zones: I and II. Zone I was treated with $0.25 \mathrm{ml}$ of acetone alone and zone II with $0.25 \mathrm{ml}$ of a monoterpene solution in acetone $\left(14\right.$ or $\left.140 \mu \mathrm{g} / \mathrm{cm}^{2}\right)$. After the acetone evaporated, the filter paper was placed in the experimental arena. A glass ring was placed on the filter paper and four larvae were placed in the center of the area enclosed by the ring. To determine the distribution of larvae on the filter paper, the TV field image was divided into two zones using the Multiple Zones Motion Monitor for Videomex software. After placing the larvae on the filter paper, their presence in each zone was recorded for $30 \mathrm{~min}$. Results were expressed as a Distribution Coefficient $(\mathrm{DC})=\mathrm{AI}-\mathrm{AII} / \mathrm{AI}+\mathrm{AII}$, where AI and AII are the areas, expressed in pixels, occupied by larvae in zone I and II, respectively (Alzogaray et al., 2000). DC values vary between 1 (maximum attraction) and -1 (maximum repellency). $\mathrm{DC}=0$ indicates that the larvae spent the same time in both zones (random distribution). There were six independent replicates of each bioassay.

\section{Knock-down}

The larvae were exposed to the vapour of monoterpenes in plastic tubes, $4 \mathrm{~cm}$ in diameter and $4 \mathrm{~cm}$ long, with plastic lids. An Eppendorf cap (Eppendorf, Hamburg, Germany) containing $100 \mu 1$ of pure monoterpene was placed in the middle of the bottom of the container. Twenty larvae were placed inside the container and then it was sealed. Control larvae were exposed to empty Eppendorf caps. Larvae lying on the bottom of the container that were unable to walk were recorded as knocked-down. The number of larvae knocked-down was recorded at different time intervals. The same intervals of time could not be used in all cases because the response to some compounds was very fast and to others very slow. Therefore, to obtain an acceptable number of observations to estimate the respective $\mathrm{KD}$ values, the results were recorded every $2 \mathrm{~min}$ for dichlorvos, $(+)-\alpha-$ pinene and (-)- $\alpha$-pinene, and every $15 \mathrm{~min}$ for the other monoterpenes. In most cases, the recording ceased when at least $90 \%$ of the larvae were knocked-down. In other cases, the experiment ceased when the compound tested failed to affect the larvae, or affected less than $50 \%$ of them, after an exposure of $490 \mathrm{~min}$. There were six independent replicates of each bioassay, but when less than $50 \%$ of larvae were affected after 490 min of exposure there were only two.

\section{Statistical analysis}

The results of the locomotor activity and repellency bioassays were analyzed using one-way ANOVA followed by Tukey test for post hoc comparisons. A Student's t-test was used to compare each DC value with the respective control group. Knockdown Time 50\% (KT50) values were calculated with their respective $95 \%$ confidence intervals $(95 \% \mathrm{CI})$ using the statistical software for correlated data developed by Throne et al. 


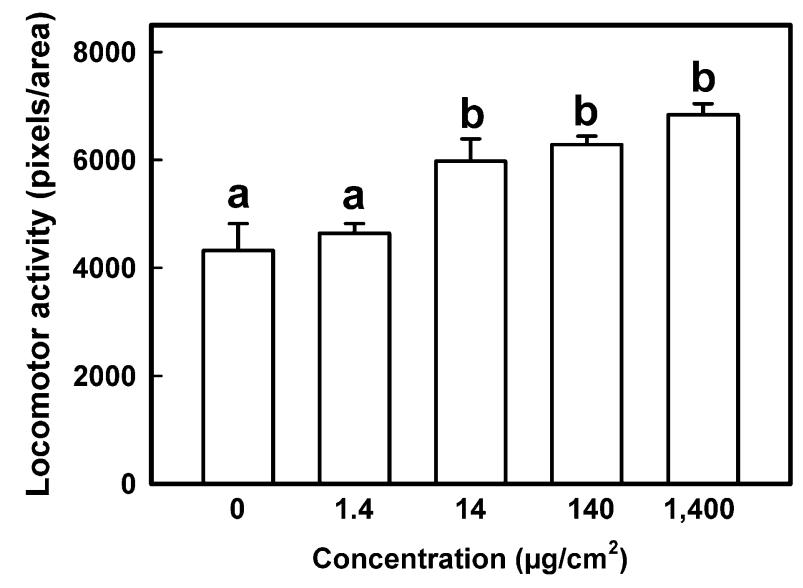

Fig. 1. Effect of menthyl acetate on the locomotor activity of first instar larvae of $B$. germanica. Each column is the mean of six replicates. Vertical lines are SEs. Columns with the same letter are not significantly different $(\mathrm{P}>0.05)$.

(1995). Differences between values were considered significant $(P<0.05)$ if the respective $95 \%$ CIs did not overlap. Linear regression was used to study the relationship between KT50 and vapour pressure of the monoterpenes. The vapour pressures of the monoterpenes were obtained from Perry \& Green (1984), Lyman (1985) and Espinosa Díaz et al. (1999).

\section{RESULTS}

We evaluated the locomotory activity of first instar larvae of $B$. germanica exposed to different concentrations of monoterpenes. It was decided a priori to use the following concentrations: $1.4,14,140$ and 1,400 $\mu \mathrm{g} / \mathrm{cm}^{2}$. However, the results for the two highest concentrations of menthone were not used because they were toxic at these concentrations and induced uncoordinated movement and resulted in knock-down of all the larvae before the experiment ended. For the same reason, the $1,400 \mu \mathrm{g} / \mathrm{cm}^{2}$ results for $(+)-\alpha$-pinene, $(-)-\alpha$-pinene, limonene and geraniol were also discarded.

Menthyl acetate was the only monoterpene that induced an increase in the locomotor activity of the larvae (Fig. 1). A concentration of $1.4 \mu \mathrm{g} / \mathrm{l}$ did not induce a response but at concentrations of 14,140 and $1,400 \mu \mathrm{g} / \mathrm{cm}^{2}$ the locomotor activity was significantly higher than that of the control group $(\mathrm{P}<0.05)$. On the other hand, there were no significant differences in the effects of these

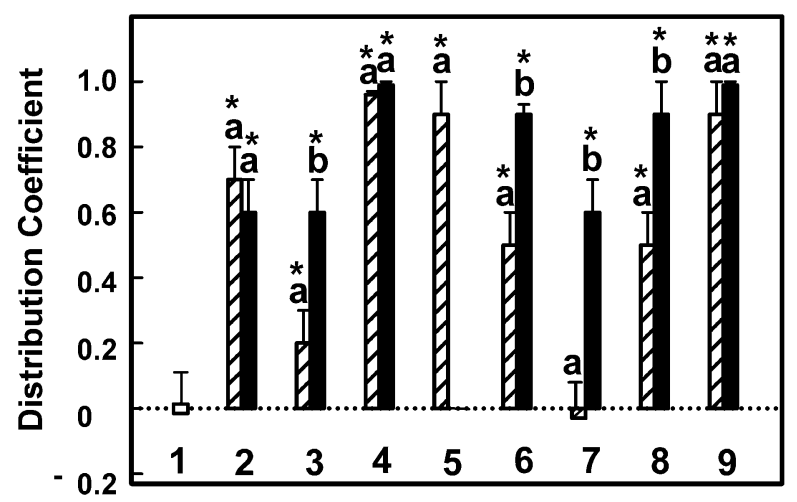

Fig. 2. Repellency of the monoterpenes for the first instar larvae of $B$. germanica. 1 - control; $2-(+)-\alpha$-pinene; $3-(-)-\alpha-$ pinene; 4 - geraniol; 5 - menthone; 6 - menthyl acetate; 7 limonene; 8 - linalool; 9 - DEET (positive control). Hatched columns - $14 \mu \mathrm{g} / \mathrm{cm}^{2}$; black columns - $140 \mu \mathrm{g} / \mathrm{cm}^{2}$. Each column is the mean of six replicates. Vertical lines represent SEs. In each pair, columns with the same letter are not significantly different $(\mathrm{P}>0.05)$. Asterisks indicate a significant difference from the control $(\mathrm{P}<0.05)$.

three concentrations $(\mathrm{P}>0.05)$. The mean locomotor activity of larvae exposed to different concentrations of the other monoterpenes varied between 3,072 and 5,455 pixels/area. These values were no significantly different from that of the controls $(\mathrm{P}>0.05)$.

Fig. 2 shows DC values of larvae exposed to 14 or 140 $\mu \mathrm{g} / \mathrm{cm}^{2}$ of monoterpenes, except menthone, which was evaluated only at the lower concentration since at the highest concentration it was toxic. There were no significant differences between the DC values of $14 \mu \mathrm{g} / \mathrm{cm}^{2}$ for limonene and the control group $(\mathrm{P}>0.05)$, but significant repellency was recorded when $140 \mu \mathrm{g} / \mathrm{cm}^{2}$ of this monoterpene was used $(\mathrm{P}<0.05)$. The single concentration of menthone $\left(14 \mu \mathrm{g} / \mathrm{cm}^{2}\right)$ tested also produced a significant repellent effect $(\mathrm{P}<0.05)$. The $\mathrm{DC}$ values for the remaining monoterpenes were significantly different from the controls for both concentrations $(\mathrm{P}<0.05)$. The two concentrations of geraniol and the highest concentration of menthyl acetate and linalool were more repellent than the same concentration of DEET (positive control).

Table 1 gives the estimated KT50 values. The decreasing order of monoterpene toxicity was as follows

TABLE 1. Knock-down of first instar larvae of B. germanica caused by monoterpenes used as fumigants.

\begin{tabular}{lccc}
\hline Monoterpene & KT50 $(\mathrm{min})$ & CI95 & Slope \pm SE \\
\hline$(+)-\alpha$-Pinene & $11.8 \mathrm{a}$ & $10.2-13.7$ & $6.9 \pm 0.5$ \\
$(-)-\alpha-$ Pinene & $14.6 \mathrm{~b}$ & $14.1-15.1$ & $12.2 \pm 0.7$ \\
Limonene & $81.0 \mathrm{c}$ & $71.0-93.0$ & $3.3 \pm 0.3$ \\
Menthone & $141.0 \mathrm{~d}$ & $111.7-183.5$ & $4.0 \pm 0.4$ \\
Linalool & $238.6 \mathrm{e}$ & $206.1-283.5$ & $8.0 \pm 0.9$ \\
Menthyl acetate & $--^{\mathrm{a}}$ & - & - \\
Geraniol & $--^{\mathrm{b}}$ & - & - \\
Dichlorvos & $9.7 \mathrm{a}$ & $8.8-10.7$ & $9.1 \pm 0.6$ \\
\hline
\end{tabular}

CI95: Confidence Interval 95\%. KT values followed by the same letter are not significantly different $(\mathrm{P}>0.05)$. ${ }^{\mathrm{a}}$ Knock-down was less than $10 \%$ after $490 \mathrm{~min}$ of exposure. ${ }^{\mathrm{b}}$ No mortality was observed after $490 \mathrm{~min}$ of exposure. 


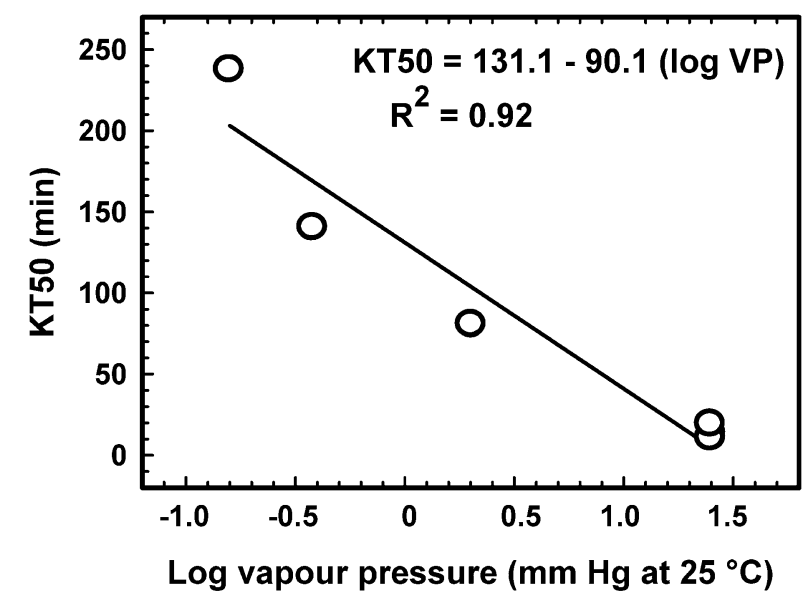

Fig. 3. Variation in the 50\% knock-down times (KT50) for monoterpenes expressed as a function of their vapour pressure. The results for the following compounds were used in this linear regression analysis: $(+)$ - $\alpha$-pinene, $(-)$ - $\alpha$-pinene, limonene, menthone and linalool. VP: vapour pressure. Each point is the mean of six replicates.

(the respective KT50 values are expressed in minutes, which are in parenthesis): (+)- $\alpha$-pinene $(11.8)>(-)-\alpha-$ pinene $(14.6)>$ limonene $(81.0)>$ menthone $(141.0)>$ linalool (238.6). We were not able to calculate the KT50 for menthyl acetate and geraniol. Following an exposure of 490 min, menthyl acetate knocked-down less than 10\% of the larvae and no larvae were knocked-down by geraniol. The KT50 for dichlorvos (positive control) was 9.7. There was no significant difference between this value and the one for $(+)-\alpha$-pinene $(\mathrm{P}>0.05)$. The KT50 for the remaining monoterpenes were significantly higher than that for dichlorvos $(\mathrm{P}<0.05)$.

Using linear regression analysis, we established the existence of a highly significant relation between the KT50 values and the natural logarithm of the monoterpene vapour pressure $(\mathrm{DF}=1.3 ; \mathrm{F}=36.5 ; \mathrm{P}=$ 0.009) (Fig. 3). The regression equation was KT50 = $131.1-90.1(\log \mathrm{VP}) ;\left(\mathrm{R}^{2}=0.92\right)$.

\section{DISCUSSION}

Certain monoterpenes produced by aromatic plants are known to have lethal and sublethal effects on insects. As there is a need for biorational pesticides to replace the environmentally damaging conventional pesticides (organophosphates, carbamates, pyrethroids), we evaluated the behavioural and toxicological responses of the German cockroach, Blattella germanica, to botanical monoterpenes.

Hyperactivity in insects is one of the first symptoms of intoxication produced by pyrethroids (Gammon, 1978; Miller \& Adams, 1982; Alzogaray et al., 1997; Alzogaray \& Zerba, 2001). Hyperactivity is responsible for the flushing-out phenomenon in which insects become more locomotory active and leave their refuges (Pinchin et al., 1980; Gualtieri et al., 1985). Hyperactivity in insects is also recorded when they are exposed to the broadspectrum repellent DEET. Concentrations of this com- pound higher than $350 \mu \mathrm{g} / \mathrm{cm}^{2}$ produce an increase in locomotor activity in the haematophagous bug $R$. prolixus (Sfara et al., 2009).

In the present study, only menthyl acetate of the seven monoterpenes evaluated induced hyperactivity in first instar larvae of $B$. germanica. This effect was apparently not associated with toxicity at the level of the central nervous system as less than $10 \%$ of the larvae showed signs of intoxication after $490 \mathrm{~min}$ of exposure to menthyl acetate, whereas they became hyperactive almost immediately.

A repellent is a chemical that causes insects to move away from the source (Dethier et al., 1960). The main use of repellents is to prevent haematophagous arthropods from biting (Katz et al., 2008). Nevertheless, $d$-limonene and some essential oils (for example mint) are used in the United States as flushing-out agents and for perimeter treatments as part of the strategies used for controlling cockroaches, ants and termites (Isman, 2010). The addition of repellents to the materials used in food packaging could prove to be an effective way of keeping insects away from products (Wong et al., 2005).

Monoterpenes with repellent properties are generally less effective, with a few exceptions, than DEET, either because of their lower repellency per se or their shorter effective life (Isman, 2006; Moore et al., 2007). When the effect of thirty-five monoterpenes upon Anopheles gambiae was evaluated, only seven of them were as repellent as DEET (Omolo et al., 2004). In the present study, all the monoterpenes used were repellent to some degree, and both concentrations of geraniol tested and the highest concentrations of menthone, menthyl acetate and linalool tested were as effective as DEET. These four substances are repellent to other species of insect (Sfara et al., 2009; Nerio et al., 2010). Moreover, there are commercial repellents containing limonene (Isman, 2010) or geraniol (Chen \& Viljoen, 2010) as the active ingredients.

In general, monoterpene vapour is less toxic for insects than other fumigant insecticides such as phosphine, ethyl bromide and the organophosphate dichlorvos (Rice \& Coats, 1994a, b; Rajendran \& Sriranjini, 2008; Lucía et al., 2009; Alzogaray et al., 2011). The concentrations of twenty-two monoterpenes that result in the death of 50\% of $M$. domestica (LC50) varied between 2 and $>2,500$ $\mu \mathrm{g} / \mathrm{cm}^{3}$, whereas the LC50 of dichlorvos was $0.01 \mu \mathrm{g} / \mathrm{cm}^{3}$ (Rice \& Coats, 1994a). In the same study, a similar tendency was recorded for Tribolium castaneum, for which most of the fourteen monoterpenes used were between 9 and $>175.6$ times less toxic than dichlorvos. However, there were some exceptions: pulegone was as toxic as dichlorvos, and $l$-fenchone was only 1.3 times less toxic.

Five out of the seven monoterpenes evaluated in the present study were considerably less toxic than dichlorvos, while $(+)-\alpha$-pinene was as toxic as this organophosphate and (-)- $\alpha$-pinene was only 1.5 times less toxic. As shown in Fig. 3, the insecticidal activity of the monoterpenes was strongly associated with their vapour pressure. These results are in accordance with a previous study in which the toxicity of twelve monoter- 
penes for B. germanica was a function of their vapour pressure (Phillips \& Appel, 2010). The very low vapour pressures of menthyl acetate and geraniol, 0.1 and 0.03 $\mathrm{mm} \mathrm{Hg}\left(25^{\circ} \mathrm{C}\right)$, respectively, could account for their very low toxicity for larvae (this study) and adults of $B$. germanica (Jang et al., 2005) and other insects ( $T$. castaneum: Rice \& Coats, 1994a, b; M. domestica: Tarelli et al., 2009; $R$. prolixus: Sfara et al., 2009).

For several decades, dichlorvos has been used for controlling agricultural and stored products pests. Domestically it is used against flies, mosquitoes, cockroaches, fleas and other insects (Tomlin, 1997). It is considered to be a hazardous air pollutant (Dowling \& Seiber, 2002). The United States Environmental Protection Agency (USEPA) planned to ban dichlorvos because of it is a carcinogen and adversely affects the central nervous system, especially of children (Binukumar \& Gill, 2010).

In Argentina, the National Administration of Medicines, Food and Technology ("Administración Nacional de Medicamentos, Alimentos y Tecnología Médica" ANMAT) prohibited the trade in domestic products containing dichlorvos due to their adverse effect on children (Ministerio de Salud, 2011). This has probably anticipated the fact that the use of dichlorvos will be restricted or prohibited due to its risk to human health. Therefore, it is important to identify substances with fumigant properties and good insecticidal activity that do not have the undesirable effects of dichlorvos. In conclusion, $(+)-\alpha-$ pinene (as a fumigant), menthyl acetate (in that it induces hyperactivity), and menthone and geraniol (as repellents) could be used for controlling $B$. germanica.

ACKNOWLEDGEMENTS. RAA, VS and ENZ are staff at the Carrera del Investigador Científico y Tecnológico of the Consejo Nacional de Investigaciones Científicas y Técnicas of Argentina (CONICET). AM is a holder of a fellowship of the Agencia Nacional de Promoción Científica y Tecnológica of Argentina (ANPCyT). The financial support for this research was provided by CONICET (PIP 2010-0887) and the ANPCyT (PICT 2008-1331).

\section{REFERENCES}

Alzogaray R.A. \& Zerba E.N. 2001: Third instar nymphs of Rhodnius prolixus exposed to $\alpha$-cyanopyrethroids: from hyperactivity to death. - Arch. Insect Biochem. Physiol. 46: 119-126.

Alzogaray R.A., Fontán A. \& Zerba E.N. 1997: Evaluation of hyperactivity produced by pyrethroid treatment on third instar nymphs of Triatoma infestans (Hemiptera: Reduviidae). Arch. Insect Biochem. Physiol. 35: 323-333.

Alzogaray R.A., Fontán A. \& Zerba E.N. 2000: Repellency of DEET to nymphs of Triatoma infestans. - Med. Vet. Entomol. 14: 6-10.

Alzogaray R.A., Lucía A., Zerba E.N. \& Masuh H.M. 2011: Insecticidal activity of essential oils from eleven Eucalyptus spp. and two hybrids: Lethal and sublethal effects of their major components on Blattella germanica. - J. Econ. Entomol. 104: 595-600.

Binukumar B.K. \& GiLl K.D. 2010: Cellular and molecular mechanisms of dichlorvos neurotoxicity: cholinergic, noncholinergic, cell signaling, gene expression and therapeutic aspects. - Indian J. Exp. Biol.48: 697-709.
BRENNER R.J. 1995: Medical and economic significance. In Rust M.K., Owens J.M. \& Reierson D.A. (eds): Understanding and Controlling the German Cockroach. Oxford University Press, Oxford, pp. 77-92.

Chen W. \& Viljoen A.M. 2010: Geraniol - A review of a commercially important fragrance material. $-S$. Afr. J. Bot. 76: 643-651.

Choi W., Park B., Ku S. \& Lee S. 2002: Repellent activities of essential oils and monoterpenes against Culex pipiens pallens. - J. Am. Mosq. Control Assoc. 18: 348-351.

Cochran D.G. 2003: Blattodea. In Resh V.H. \& Cardé R.T. (eds): Encyclopedia of Insects. Academic Press, New York, pp. 123-126.

Cornelius M.L., Grace J.K. \& Yates J.R. 1997: Toxicity of monoterpenoids and other natural products to the Formosan subterranean termite (Isoptera: Rhinotermitidae). - J. Econ. Entomol. 90: 320-325.

Dethier V.G., Browne L.B. \& Smith C.N. 1960: The designation of chemicals in terms of the responses they elicit from insects. - J. Econ. Entomol. 53: 134-136.

Dowling K.C. \& SeIBER J.N. 2002: Importance of respiratory exposure to pesticides among agricultural. - Int. J. Toxicol. 21: $371-381$.

ENAN E.E. 2001: Insecticidal activity of essential oils: octopaminergic sites of action. - Comp. Biochem. Physiol. (C) 130: 325-337.

ENAN E.E. 2005: Molecular and pharmacological analysis of an octopamine receptor from American cockroach and fruit fly in response to plant essential oils. - Arch. Insect Biochem. Physiol. 59: 161-171.

Espinosa Diaz M.A., Guetachew T., Landy P., Jose J. \& VoILley A. 1999: Experimental and estimated saturated vapour pressures of aroma compounds. - Fluid Phase Equilib. 157: 257-270.

Gammon D.W. 1978: Neural effects of allethrin on the free walking cockroach Periplaneta americana: an investigation using defined doses at 15 and $32^{\circ}$ C. - Pestic. Sci. 9: 79-91.

Gualtieri J.M., Nelson M. \& Cichero J.A. 1985: Presente y perspectiva del control químico. In Carcavallo R.U., Rabinovich J.E. \& Tonn R.J. (eds): Factores Biológicos y Ecológicos en la Enfermedad de Chagas. Centro Panamericano de Ecología Humana y Salud, Organización Panamericana de la Salud, Servicio Nacional de Chagas y Ministerio de Salud y Acción Social de la República Argentina, pp. 319-329.

HummelbrunNer L.A. \& Isman M.B. 2001: Acute, sublethal, antifeedant, and synergistic effects of monoterpenoid essential oil compounds on the tobacco cutworm, Spodoptera litura (Lep., Noctuidae). J. Agric. Food Chem. 49: 715-720.

Isman M.B. 2000: Plant essential oil for pest and disease management. - Crop Prot. 19: 603-608.

IsMAN M.B. 2006: The role of botanical insecticides, deterrents and repellents in modern agriculture and an increasingly regulated world. - Annu. Rev. Entomol. 51: 45-66.

Isman M.B. 2010: Botanical insecticides, deterrents, repellents and oils. In Singh B.P. (ed.): Industrial Crops and Uses. CABI, Oxfordshire, pp. 433-445.

Isman M.B. \& AKhtaR Y. 2007: Plant natural products as a source for developing environmentally acceptable insecticides. In Ishaaya I., Nauen R. \& Horowitz A.R. (eds): Insecticides Design Using Advanced Technologies. Springer, Berlin, pp. 235-248.

Isman M.B. \& Machial C.M. 2006: Pesticides based on plant essential oils: from traditional practice to commercialization In Rai M. \& Carpinella M.C. (eds): Naturally Occurring Bioactive Compounds. Advances in Phytomedicine, Vol. 3. Elsevier, London, pp. 29-44. 
Isman M.B. \& PALuch G. 2011: Needles in the haystack: exploring chemical diversity of botanical insecticides. In López O. \& Fernández-Bolaños J.G. (eds): Green Trends in Insect Control. Royal Society of Chemistry, Cambridge, London, pp. 248-265.

Isman M.B., Machial C.M., Miresmailli S. \& Bainard L.D. 2007: Essential oil-based pesticides: new insights from old chemistry. In Ohkawa H., Miyagawa H. \& Lee P. (eds): Pesticide Chemistry. Wiley, Weinheim, pp. 201-209.

JANG Y.-S., Yang Y.-C., ChoI D.-S. \& AhN Y.-J. 2005: Vapor phase toxicity of marjoram oil compounds and their related monoterpenoids to Blattella germanica (Orthoptera: Blattellidae). - J. Agric. Food Chem. 53: 7892-7898.

KarR L.L., Drewes C.D. \& Coats J.R. 1990: Toxic effects of $d$-limonene in the earthworm Eisenia fetida (Savigny). Pest. Biochem. Physiol. 36: 175-186.

Katz T.M., Miller J.H. \& Hebert A.A. 2008: Insect repellents: Historical perspectives and new developments. - J. Am. Acad. Dermatol. 58: 865-871.

Lee S., Peterson C.J. \& Coats J.R. 2003: Fumigation toxicity of monoterpenoids to several stored product insects. - J. Stored Prod. Res. 39: 77-85.

López M.D. \& Pascual-Villalobos M.J. 2010: Mode of inhibition of acetylcholinesterase by monoterpenoids and implications for pest control. - Ind. Crop. Prod. 31: 284-288.

Lucía A., González Audino P., Seccacini E., Licastro S., Zerba E. \& MAsun H. 2007: Larvicidal effect of Eucalyptus grandis essential oil and turpentine and their major components on Aedes aegypti larvae. - J. Am. Mosq. Control Assoc. 23: 299-303.

Lucía A., Licastro S., Zerba E., González Audino P. \& Masuh H. 2009: Sensitivity of Aedes aegypti adults (Diptera: Culicidae) to the vapors of Eucalyptus essential oils. - Bioresour. Technol. 100: 6083-6087.

LyMAN W.J. 1985: Estimation of physical properties. In Neely W.B. \& Blau G.E. (eds): Environmental Exposure From Chemicals. Vol. 1. CRC Press, Boca Raton, pp. 13-47.

Miller T.A. \& Adams M.E. 1982: Mode of action of pyrethroids. In Coats J.R. (ed.): Insecticide Mode of Action. Academic Press, New York, pp. 3-27.

Ministerio de SAlud 2011: Químicos prohibidos y restringidos en Argentina [Chemicals Banned and Restricted in Argentina.] Ministerio de Salud de la Nación Argentina, Buenos Aires, 19 pp. [in Spanish]

Moore S.J., Lenglet A. \& Hill N. 2007: Plant-based insect repellents. In Debboun M., Frances S.P. \& Strickman D. (eds): Insect Repellents. CRC Press, Boca Raton, pp. 275-303.

Nerio L.S., Olivero-Verbel J. \& Stashenko E. 2010: Repellent activity of essential oils: A review. - Bioresour. Technol. 101: 372-378.

Omolo M.O., Okinyo D., Ndiege I.O., Lwande W. \& Hassanali A. 2004: Repellency of essential oils of some Kenyan plants against Anopheles gambiae. - Phytochemistry 65: 2797-2802.

Perry R.H. \& Green D. 1984: Perry's Chemical Handbook. Physical and Chemical data. McGraw-Hill, New York, 2640 pp.
Petrakis P.V., Roussis V., Papadimitriou D., Vagias C. \& TsitSIMPIKOU C. 2005: The effect of terpenoid extracts from 15 pine species on the feeding behavioral sequence of the late instars of the pine processionary caterpillar Thaumetopoea pityocampa. - Behav. Process. 69: 303-322.

Picollo M.I., Toloza A.C., Mougabure Cueto G., Zygadlo J. \& ZERBA E. 2008: Anticholinesterase and pediculicidal activities of monoterpenoids. - Fitoterapia 79: 271-278.

Phillips A.K. \& Appel A.G. 2010: Fumigant toxicity of essential oils to the German cockroach (Dictyoptera: Blattellidae). $-J$. Econ. Entomol. 103: 781-90.

Pinchin R., de Oliveira Filho A.M. \& Pereira A.C.B. 1980: The flushing-out activity of pyrethrum and synthetic pyrethroids on Pastrongilus megistus, a vector of Chagas's disease. - Trans. R. Soc. Trop. Med. Hyg. 75: 691-694.

RaJendRan S. \& SRIRANIINI V. 2008: Plant products as fumigants for stored-product insect control. - J. Stored Prod. Res. 44: 126-135.

RiCE P.J. \& COATS J.R. 1994a: Insecticidal properties of several monoterpenoids to the house fly (Diptera: Muscidae), red flour beetle (Coleoptera: Tenebrionidae), and southern corn rootworm (Coleoptera: Chrysomelidae). - J. Econ. Entomol. 87: 1172-1179.

RICE P.J. \& COATS J.R. 1994b: Insecticidal properties of monoterpenoid derivatives to the house fly (Diptera: Muscidae) and red flour beetle (Coleoptera: Tenebrionidae). - Pestic. Sci. 41: 195-202.

Sfara V., Zerba E.N. \& Alzogaray R.A. 2009: Fumigant insecticidal activity and repellent effect of five essential oils and seven monoterpenes on first instar nymphs of Rhodnius prolixus. - J. Med. Entomol. 46: 511-515.

Sfara V., Mougabure Cueto G.A., Zerba E.N. \& Alzogaray R.A. 2011: Adaptation of the repellency response to DEET in Rhodnius prolixus. - J. Insect Physiol. 57: 1431-1436.

Tarelli G., Zerba E.N. \& Alzogaray R.A. 2009: Toxicity to vapor exposure and topical application of essential oils and monoterpenes on Musca domestica L. (Diptera: Muscidae). J. Econ. Entomol. 102: 1383-1388.

Throne J.E., Weaver D.K, Chew V. \& Baker J.E. 1995: Probit analysis of correlated data: multiple observations over time at one concentration. - J. Econ. Entomol. 88: 1510-1512.

Tisserand R. \& Balacs T. 1995: Essential Oil Safety. Livingstone, London, $279 \mathrm{pp}$.

Toloza A.C., Zygadlo J., Cueto G.M., Biurrun F., Zerba E. \& Picollo M.I. 2006: Fumigant and repellent properties of essential oils and component compounds against permethrinresistant Pediculus humanus capitis (Anoplura: Pediculidae) from Argentina. - J. Med. Entomol. 43: 889-895.

TomLin C.D.S. 1997: The Pesticide Manual. 11th ed. BCPC, Farnham, 1608 pp.

Wong K.K.Y., Signal F.A., Campion S.H. \& Motion R.L. 2005: Citronella as an insect repellent in food packaging. $-J$ Agric. Food Chem. 53: 4633-4636.

Zahran H.E.D.M. \& ABdelgaleIL S.A.M. 2011: Insecticidal and inhibitory properties of monoterpenes on Culex pipiens L. (Diptera: Culicidae). - J. Asia-Pacific Entomol. 14: 46-51.

Received April 10, 2012; revised and accepted October 1, 2012 